\title{
1, 2(2, 2-dihydroxy Benzelidenamine) Phenyl Complexes as Corrosion Inhibitor for Carbon Steel in Hydrochloric Acid
}

\author{
Dina A.Najeeb ${ }^{1}$ and Taghried A. Salman ${ }^{1}$ \\ ${ }^{1}$ Department of Chemistry, College of Science, Al-Nahrain University, Baghdad-Iraq. \\ Corresponding Author: dinachem70@gmail.com,dr.taghried.ali@gmail.com
}

\begin{abstract}
The corrosion inhibition on carbon steel in $1 \mathrm{MHCl}$ by $1,2(2,2$-dihydroxy benzelidenamine) phenyl and its complexes was studied at different concentrations by "weight loss method". Data mark, for the compound shows good performance. These measurements show that the inhibition efficiency obtained by these complexes increased by increasing their concentration. The inhibition efficiency follow the order $\mathrm{Co}>\mathrm{Ni}>\mathrm{Cu}$. The activation and adsorption thermodynamic parameters were determined and discussed. The surface coverage $(\Theta)$ of the inhibitors conform "Langmuir adsorption isotherm". (Morphology) of the carbon steel alloy has been examine using "scanning electron microscopy" in existence and inexistence of inhibitor.
\end{abstract}

[DOI: $10.22401 /$ JNUS.21.3.02]

Keywords: Metal complexes, Schiff base, inhibition efficiency, Weight loss measurements.

\section{Introduction}

A number of Schiff bases were known to be applicable as corrosion inhibitors for metal in acidic environments [1-4].The main features of the prepared ligand with $\mathrm{O}, \mathrm{S}$ and $\mathrm{N}$ as "polar groups" and conjugated double bonds in their shapes have been detected to be good "corrosion inhibitors" for so many complexes and alloys in corrosion media [5,10]. Carbon steel alloy has been used under so many different conditions in chemical and allied industries in handling alkaline, acid and salt solutions due to its good mechanical property. Adsorption of inhibitor is control by the electronic structure of the inhibiting complexes [11, 13], and also by steric factors, aromaticity, electron density at the donor atoms and also by the existence of functional groups such as $\mathrm{C}=\mathrm{NH},-\mathrm{N}=\mathrm{N}-,-\mathrm{CHO}, \mathrm{R}-\mathrm{OH}$, $\mathrm{C}=\mathrm{C}$, etc.. The Schiff base and its metal complexes effect on carbon steel corrosion in $1 \mathrm{~N} \mathrm{HCl}$ solution were studied by weight loss method for different concentrations. The realization of carbon steel alloy corrosion was always a major subject of great practical and theoretical benefit. Chloride, sulphate and nitrate ions in solution were especially" aggressive" so it speeds up corrosion. The best way to protect alloy from corrosion was to use corrosion inhibitors.1, 2 (2, 2-dihydroxy benzelidenamine) phenyl and its complexes were prepared and characterized via (elemental analysis), FTIR, UV-Vis, (Molar conductance) and theoretical study in previous work [14]. In this paper the inhibition efficiency of 1,2(2,2-dihydroxy benzelidenamine) phenyl and its complexes have been examined for the corrosion of carbon steel in $1 \mathrm{M} \mathrm{HCl}$.

\section{Experimental details}

Carbon steel alloy has purity more than 98.8\% have been used in this research. The aggressive $1 \mathrm{M} \mathrm{HCl}$ was prepared by diluting the Analytical Grade $37 \% \mathrm{HCl}$ with bidistilled water. The ligand and its metal complexes $(\mathrm{Co}, \mathrm{Ni}$ and $\mathrm{Cu})$ were being prepared according to the procedure described in paper [14]. The ligand prepared according to scheme (1).

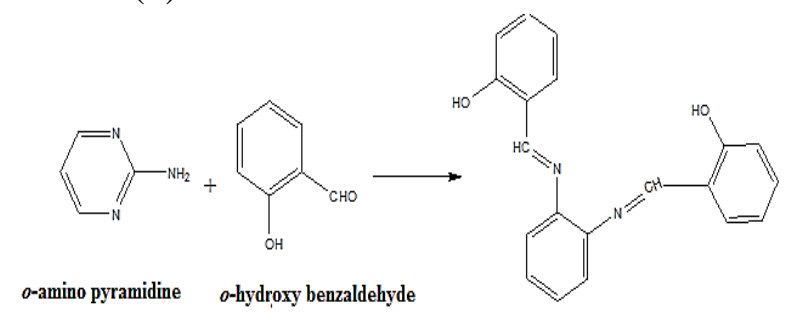

\section{Scheme (1): Reaction scheme for preparing ligand.}

Inhibitor solutions with concentrations of 100 to 500 ppm being prepared by dissolving the required amount of the prepare Schiff base and its transition metal complexes in $50 \mathrm{ml}$ of $1 \mathrm{M} \mathrm{HCl}$. The blank solution has been prepared as $50 \mathrm{ml}$ of $1 \mathrm{M} \mathrm{HCl}$ without inhibitor. Carbon steel specimens are cleaned with different grade emery papers and degreased with 
acetone. The initial weight of each specimen was measured using an analytical balance and then the specimens were immersed in $1 \mathrm{M} \mathrm{HCl}$ solutions without and with different concentrations of the inhibitor for different time at room temperature. At the end, the specimens were washed and reweighed.

The (morphology surface)of corrosion output, on carbon steel sample after $24 \mathrm{~h}$ immersion in $1 \mathrm{M} \mathrm{HCl}$ in the existence and inexistence of $500 \mathrm{ppm}$ of ligand and its metal complexes has been studied by SEM(inspect S50).

\section{Results And Discussion}

Weight loss measurements

The corrosion rate $(\mathrm{CR})$ has been estimated from this equation [15]:

$$
\mathrm{CR}=\left(\mathrm{m}_{1}-\mathrm{m}_{2}\right) / \mathrm{S} . \mathrm{t}
$$

$\left(\mathrm{m}_{1}\right)$ and $\left(\mathrm{m}_{2}\right)$ are masses of the specimen before and after corrosion respectively, $\mathrm{S}$ area of the specimen, $\mathrm{t}$ corrosion time.
The corrosion rate of the specimen immersed in $1 \mathrm{M} \mathrm{HCl}$ solution at various immersion time (1, 2 and 3) hours were 1.29, 1.86 and $2.80 \mathrm{mg} / \mathrm{cm}^{2} . \mathrm{h}$, respectively. After each immersion time the alloy be removed and cleaned. Dryish and reweight to obtain weight loss. Inhibition efficiency (PE \%) was obtained by using the following equation [16] :

$$
\mathrm{PE} \%=\left(1-\mathrm{CR} / \mathrm{CR}^{\circ}\right) \mathrm{x} 100
$$

$\mathrm{CR}$ and $\mathrm{CR}^{\circ}$ are respectively, the corrosion rate $\left(\mathrm{mg} / \mathrm{cm}^{2} / \mathrm{h}\right)$ of carbon steel specimen with and without inhibitor. Expression = (1-CR/CR ${ }^{\circ}$ was used to determine degree of surface coverage $(\Theta)$. When the concentration of inhibitor increase the inhibitor efficiency (PE \%) increase. Amounts of (PE \%), (CR) and $(\Theta)$ for Co complex at different concentrations and different periods of time are listed in Table(1).

Table (1)

$P E \%, C R$ and $\theta$ by Co-complex calculated by mass loss test with carbon steel alloy in $1 \mathrm{M} \mathrm{HCl}$

\begin{tabular}{|c|c|c|c|c|}
\hline Concentration ppm & Weight loss (mg) & PE \% & $\boldsymbol{\theta}$ & $\overline{C R}\left(\mathrm{mg} / \mathrm{cm}^{2} \cdot \mathrm{h}\right)$ \\
\hline 100 & 1.2 & 60.5 & 0.605 & 0.510 \\
\hline 200 & 0.8 & 62.1 & 0.621 & 0.489 \\
\hline 300 & 0.4 & 63.33 & 0.633 & 0.473 \\
\hline 400 & 0.2 & 66.6 & 0.666 & 0.431 \\
\hline 500 & 0.09 & 68.2 & 0.682 & 0.411 \\
\hline \multicolumn{5}{|c|}{ Experiment period: 2 hours } \\
\hline 100 & 1.8 & 79.4 & 0.794 & 0.385 \\
\hline 200 & 1.4 & 80.5 & 0.805 & 0.362 \\
\hline$\overline{300}$ & 0.8 & 82.8 & 0.828 & 0.320 \\
\hline 400 & 0.5 & 83.8 & 0.838 & 0.302 \\
\hline$\overline{500}$ & 0.1 & 85.9 & 0.859 & 0.263 \\
\hline \multicolumn{5}{|c|}{ Experiment period: 3 hours } \\
\hline 100 & 2.2 & 87.7 & 0.877 & 0.345 \\
\hline 200 & 1.7 & 88.8 & 0.888 & 0.315 \\
\hline 300 & $\begin{array}{l}1.3 \\
\end{array}$ & 89.7 & 0.897 & 0.289 \\
\hline 400 & 1.1 & 90.0 & 0.900 & 0.279 \\
\hline$\overline{500}$ & 0.7 & 92.5 & 0.925 & 0.211 \\
\hline
\end{tabular}
(Experiment periods: 1hour, 2 hours, and 3 hours).

Values of inhibition efficiency, corrosion rate and degree of surface coverage for $\mathbf{N i}$ complex at different concentrations and different periods of time are listed in Table (2). 
Table (2)

$\% P E, C R$ and $\theta$ by Ni-complexes evaluated by mass loss experiment with carbon steel in $1 M$ hydrochloric acid (Experiment period: 1hour, 2 hours, and 3 hours).

\begin{tabular}{|c|c|c|c|c|}
\hline Concentration ppm & Weight loss (mg) & PE \% & $\boldsymbol{\theta}$ & CR $\left(\mathrm{mg} / \mathrm{cm}^{2} . \mathrm{h}\right)$ \\
\hline 100 & 1.6 & 53.8 & 0.538 & 0.596 \\
\hline 200 & 1.3 & 59.3 & 0.593 & 0.525 \\
\hline 300 & 0.6 & 59.8 & 0.598 & 0.519 \\
\hline 400 & 0.5 & 65.4 & 0.654 & 0.447 \\
\hline 500 & 0.4 & 65.7 & 0.657 & 0.443 \\
\hline \multicolumn{5}{|c|}{ Experiment period: 2 hours } \\
\hline 100 & 2 & 70.3 & 0.703 & 0.553 \\
\hline 200 & 1.9 & 74.5 & 0.745 & 0.475 \\
\hline 300 & 1.2 & 75.1 & 0.751 & 0.463 \\
\hline 400 & 0.9 & 81.3 & 0.813 & 0.348 \\
\hline 500 & 0.7 & 83.1 & 0.831 & 0.315 \\
\hline \multicolumn{5}{|c|}{ Experiment period: 3 hours } \\
\hline 100 & 2.8 & 86.0 & 0.860 & 0.392 \\
\hline 200 & 2.3 & 86.8 & $\begin{array}{c}0.868 \\
\end{array}$ & 0.370 \\
\hline 300 & 1.8 & 86.9 & 0.869 & 0.366 \\
\hline 400 & 1.6 & 88.8 & 0.888 & 0.315 \\
\hline 500 & 0.9 & 89.0 & 0.890 & 0.309 \\
\hline
\end{tabular}

The inhibition efficiency amounts, corrosion rate $(\mathrm{CR})$ and degree of surface coverage $(\Theta)$ for $\mathrm{Cu}$-complex with different concentrations, and different time are listed in Table (3).

Table (3)

\%PE, CR and $\mathrm{\theta}$ by Cu-complex calculated by mass loss test with carbon steel alloy in $1 \mathrm{M} \mathrm{HCl}$ (Experiment period: 1hour, 2 hours, and 3 hours).

\begin{tabular}{|c|c|c|c|c|c|}
\hline Concentration ppm & Weight loss (mg) & PE \% & $\boldsymbol{\theta}$ & \multicolumn{2}{|c|}{ CR (mg/cm².h) } \\
\hline 100 & 2.5 & 45.1 & 0.451 & \multicolumn{2}{|c|}{0.709} \\
\hline 200 & 2.1 & 45.3 & 0453 & \multicolumn{2}{|c|}{0.705} \\
\hline 300 & 1.6 & 48.1 & 0.481 & \multicolumn{2}{|c|}{0.669} \\
\hline 400 & 1.3 & 48.9 & 0.489 & \multicolumn{2}{|c|}{0.659} \\
\hline 500 & 0.8 & 52.8 & 0.528 & \multicolumn{2}{|c|}{0.609} \\
\hline \multicolumn{6}{|c|}{ Experiment period: 2 hours } \\
\hline 100 & 3.1 & 63.3 & 0.633 & \multicolumn{2}{|c|}{0.682} \\
\hline 200 & 2.8 & 63.8 & 0.638 & \multicolumn{2}{|c|}{0.673} \\
\hline 300 & 2.4 & 66.4 & 0.664 & \multicolumn{2}{|c|}{0.625} \\
\hline 400 & 1.7 & 71.1 & 0.711 & \multicolumn{2}{|c|}{0.539} \\
\hline 500 & 1.2 & 73.7 & 0.737 & \multicolumn{2}{|c|}{0.490} \\
\hline \multicolumn{6}{|c|}{ Experiment period: 3 hours } \\
\hline 100 & 3.5 & 78.6 & \multicolumn{2}{|c|}{0.786} & 0.598 \\
\hline 200 & 3 & 80.6 & \multicolumn{2}{|c|}{0.806} & 0.544 \\
\hline 300 & 2.9 & 81.8 & \multicolumn{2}{|c|}{0.818} & 0.511 \\
\hline 400 & 2.3 & 82.3 & \multicolumn{2}{|c|}{0.823} & 0.496 \\
\hline 500 & 1.6 & 83.1 & \multicolumn{2}{|c|}{0.831} & 0.475 \\
\hline
\end{tabular}


It is obvious from Tables 1, 2 and 3 that all these complexes inhibit the corrosion of carbon steel alloy at all concentrations have already been used in this work. The (PE \%) for all of these complexes increases as concentrations of metal complexes increase. The information that we obtain from this study showed appreciable corrosion inhibition of the metal complexes disposal against corrosion of carbon steel alloy in a $1 \mathrm{MHCl}$ solution. The Schiff base has inhibition efficiencies towards the carbon steel may be expected to coordination by the (donoracceptor) reaction between the unshared electron pairs of donor atoms of the ligand and its metals [17, 18].Weight loss measurements of carbon steel decrease with increasing concentrations of ligand and Its metal complexes as shown in Figures 1, 2 and 3.

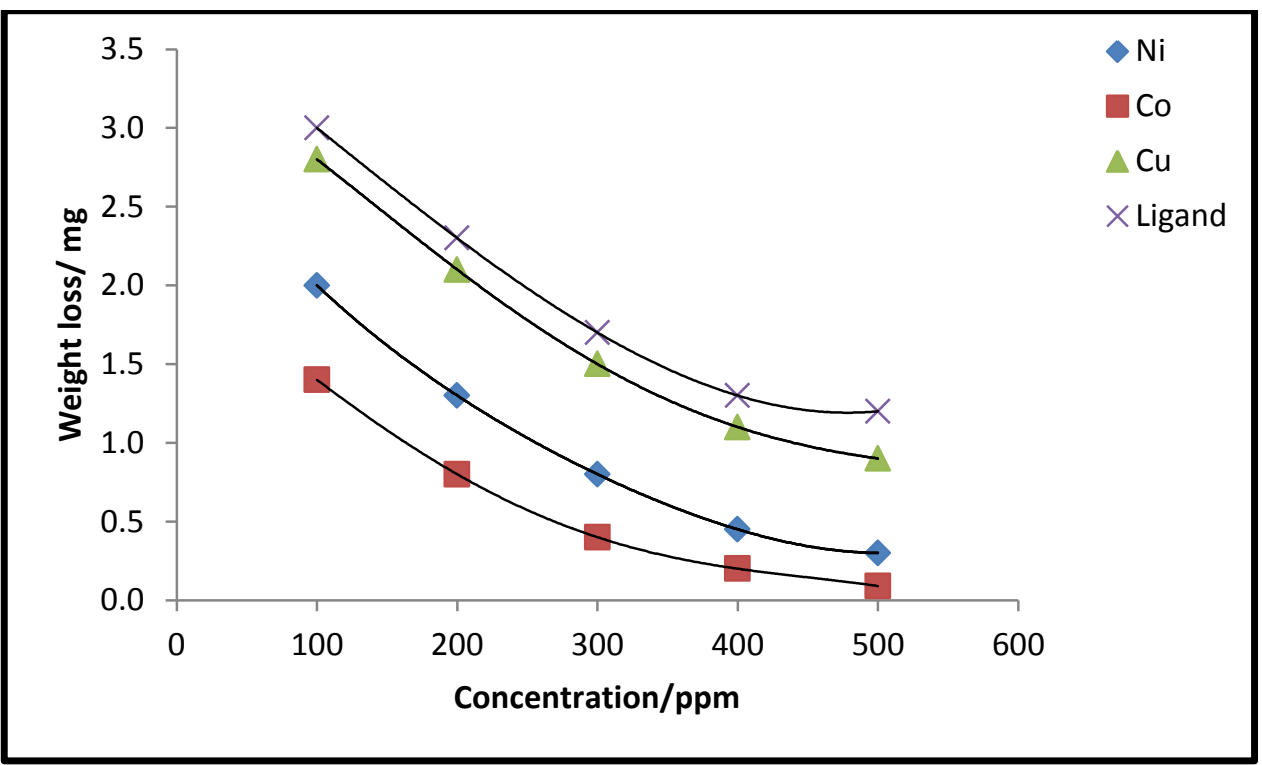

Fig.(1): Weight loss test for carbon steel versus concentrations in $1 \mathrm{M} \mathrm{HCl}$ in the absence and occurring of $\mathrm{Ni}$, Co and $\mathrm{Cu}$ complexes and its ligand forl hour.

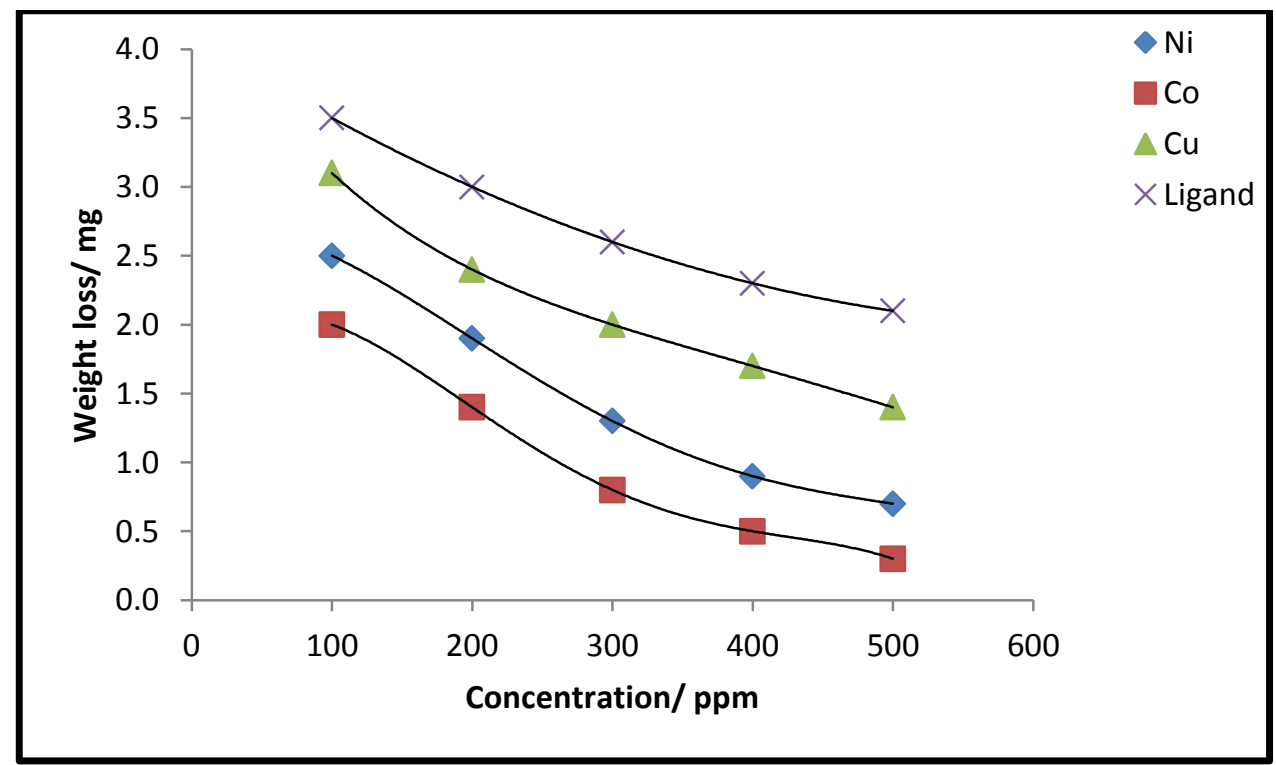

Fig. (2): Weight loss test for carbon steel versus concentrations in $1 \mathrm{M} \mathrm{HCl}$ in the absence and occurring of $\mathrm{Ni}$, Co and $\mathrm{Cu}$ complexes and its ligand for 2 hours. 


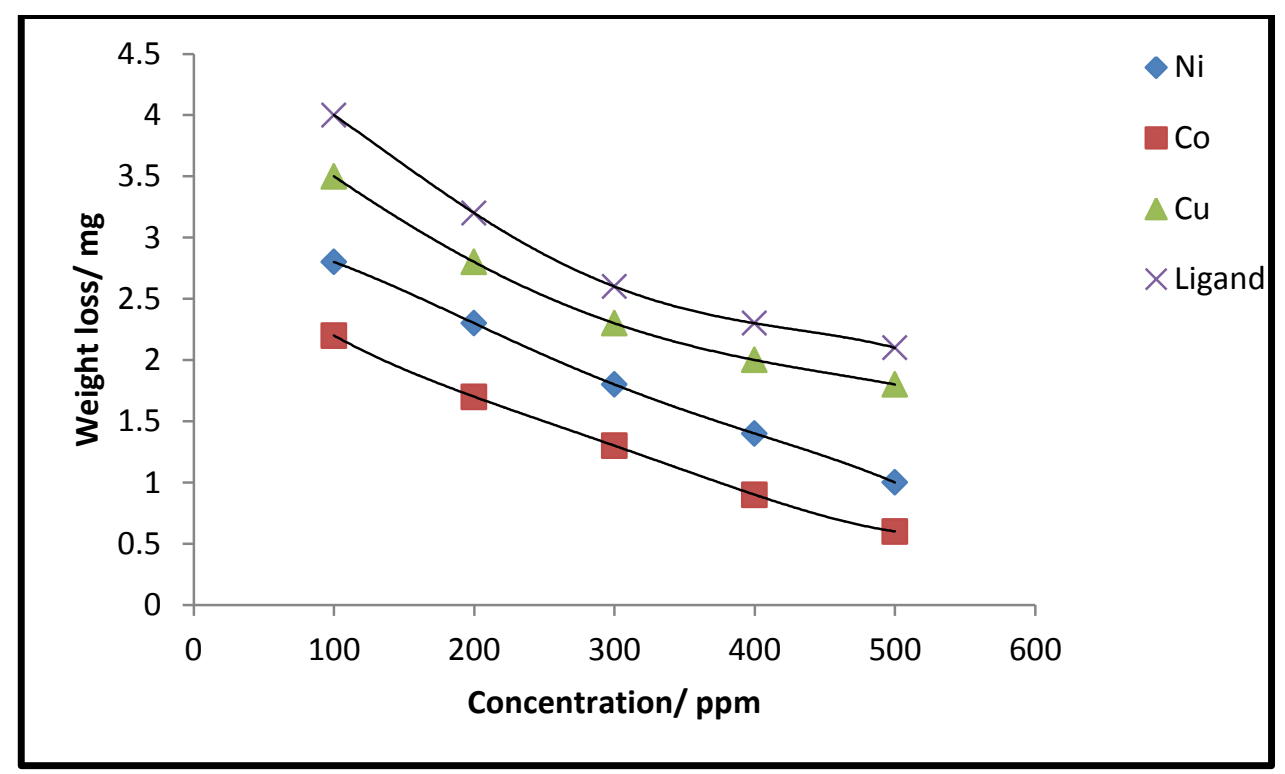

Fig. (3): Weight loss test for carbon steel versus concentrations in $1 \mathrm{M} \mathrm{HCl}$ in the absence and presence of $\mathrm{Ni}$, Co and $\mathrm{Cu}$ complexes and its ligand for 3 hours.

The inhibition efficiency increased with increased concentration of the metal complexes. This suggests that corrosion inhibition is a result of adsorption of inhibitor on the metal surface and the complexes acts as adsorption inhibitors. Best inhibition efficiency at excessive concentration may be indicating a larger coverage of metal with inhibitor molecules [19,21]. Difference in inhibition efficiency might be due to the difference in the stability and solubility of complexes in the acid solution. The metal complexes exhibit greater inhibition efficiency than the free ligand. The metal complexes show great efficiency than Schiff base may be referring to their larger size and molecular planarity. Thus, the order of inhibition efficiency is Co-complexes $>\mathrm{Ni}$-complexes > $\mathrm{Cu}$-complexes $>$ Ligand [22].

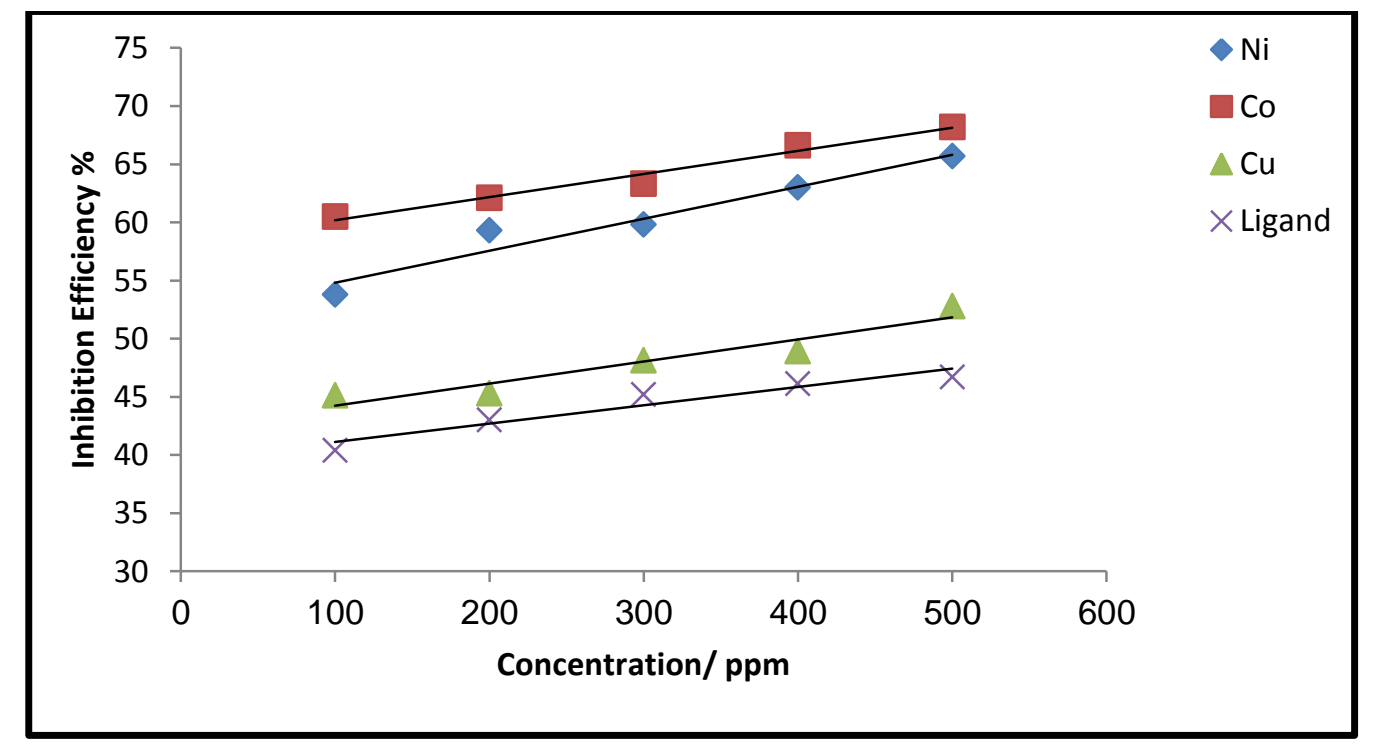

Fig.(4): The \%PE against concentration of metal complexes and its ligand for carbon steel (immersion time: one hour). 


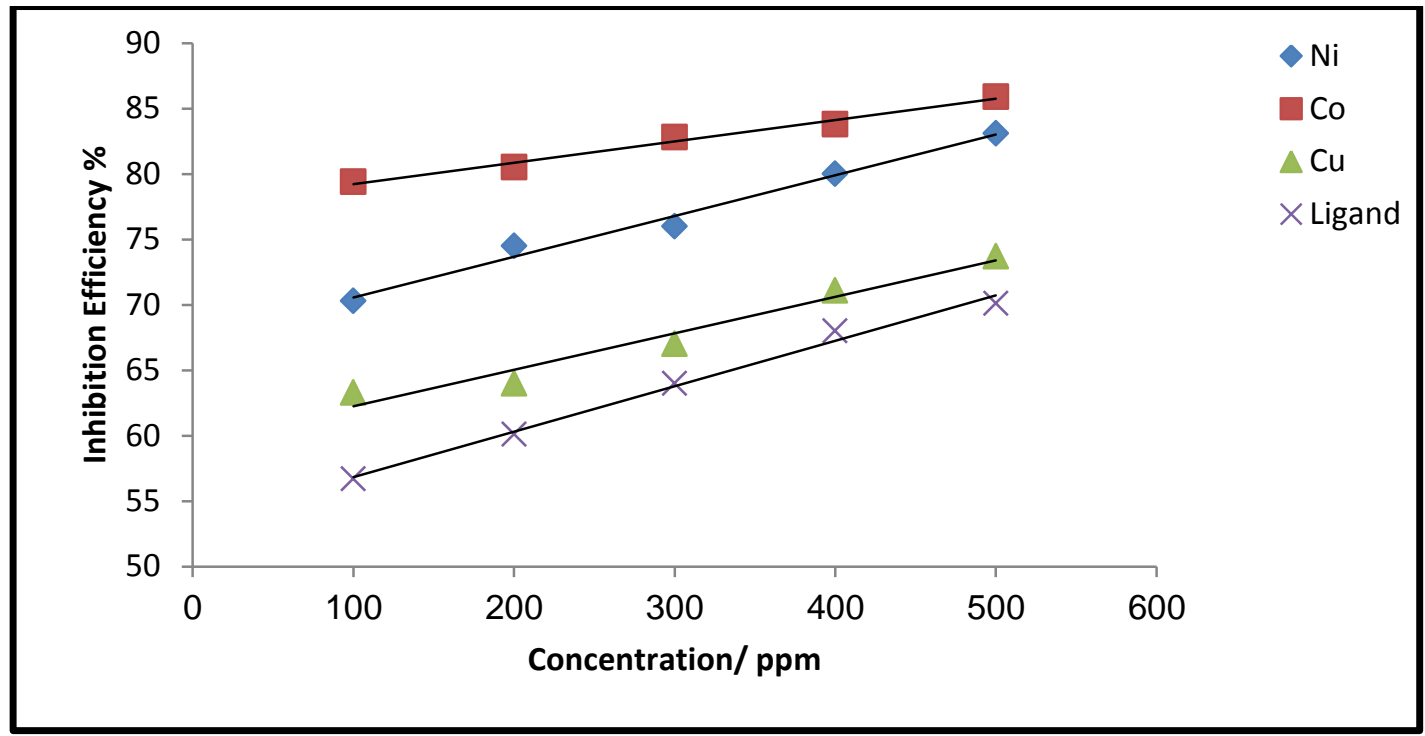

Fig.(5): The \%PE against concentration of metal complexes and its ligand for carbon steel (immersion time: two hours).

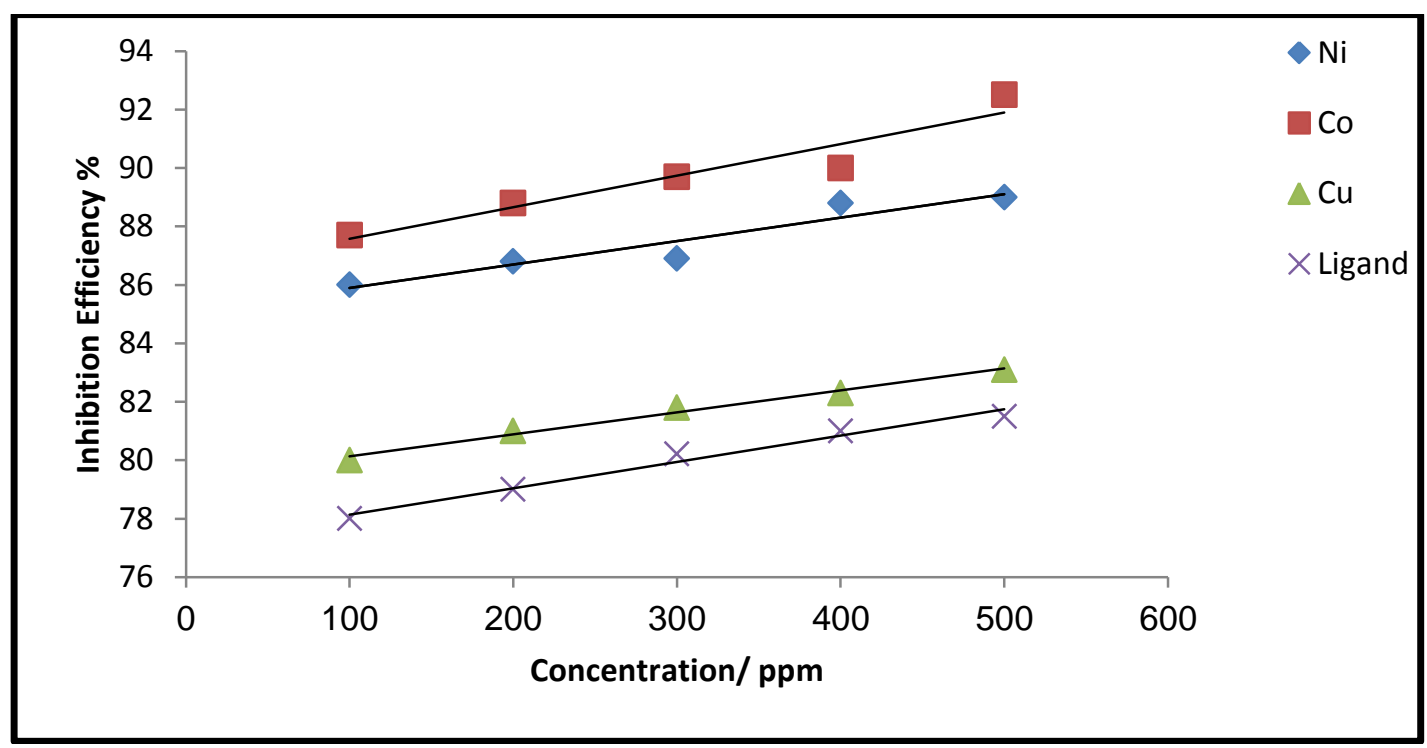

Fig.(6): The \%PE against concentration of metal complexes and its ligand for carbon steel (immersion time: three hours).

\section{Corrosion kinetics of carbon steel in $\mathrm{HCl}$} acid with inhibitor

Figurs.7, 8 and 9 shows $\log \mathrm{W}_{\mathrm{i}} / \Delta \mathrm{Wt}$ (initial weight over difference weight of carbon steel at time $\mathrm{t}$ ) is variation with time for each complexes. The straight lines, which complemented that the reaction with carbon steel alloy obeys first order reaction law [23, 24].

$\log \mathrm{W}_{\mathrm{i}} / \Delta \mathrm{Wt}=-\mathrm{k} / 2.303 \mathrm{t}-\log \mathrm{Wi}$

The rate constants $(\mathrm{k})$ measured from figures 7,8 and 9 are listed in Table (4). 


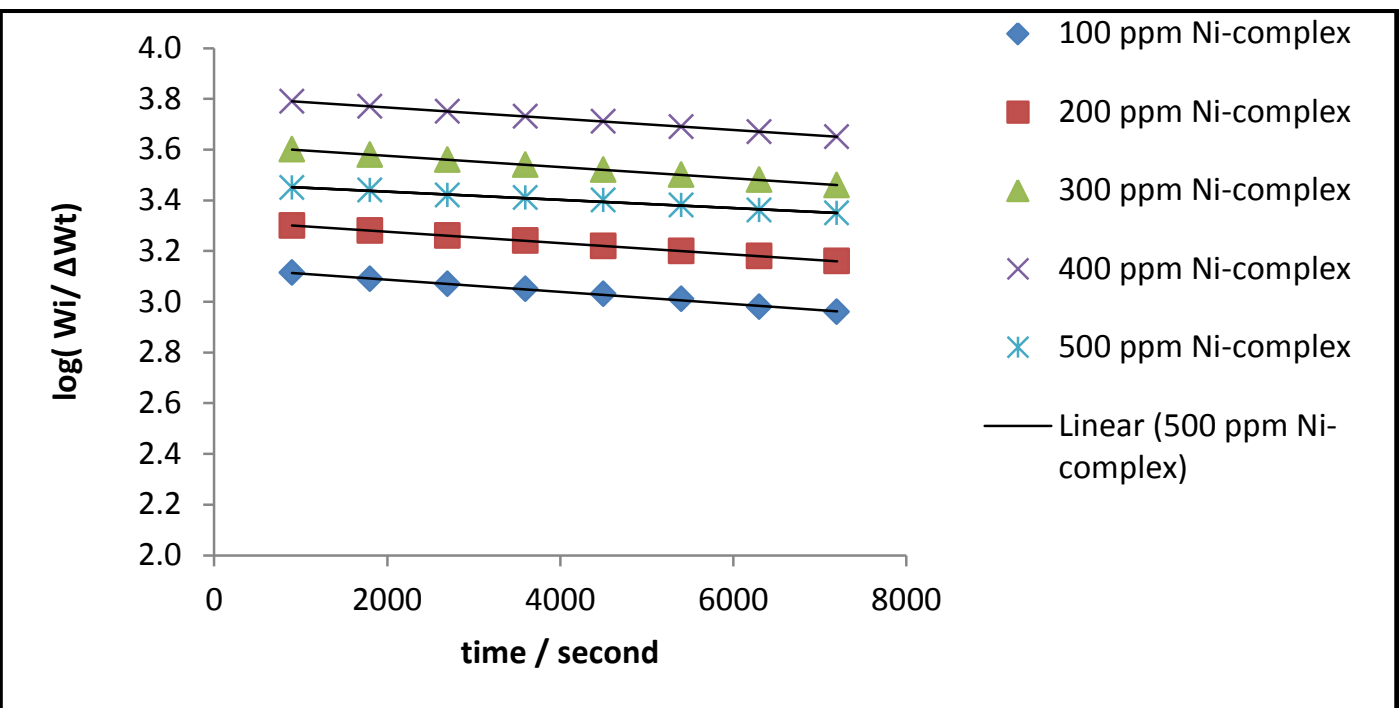

Fig.(7): Kinetic measurements of corrosion for carbon steel in $\mathrm{HCl}$ at different concentrations of Ni-complexes.

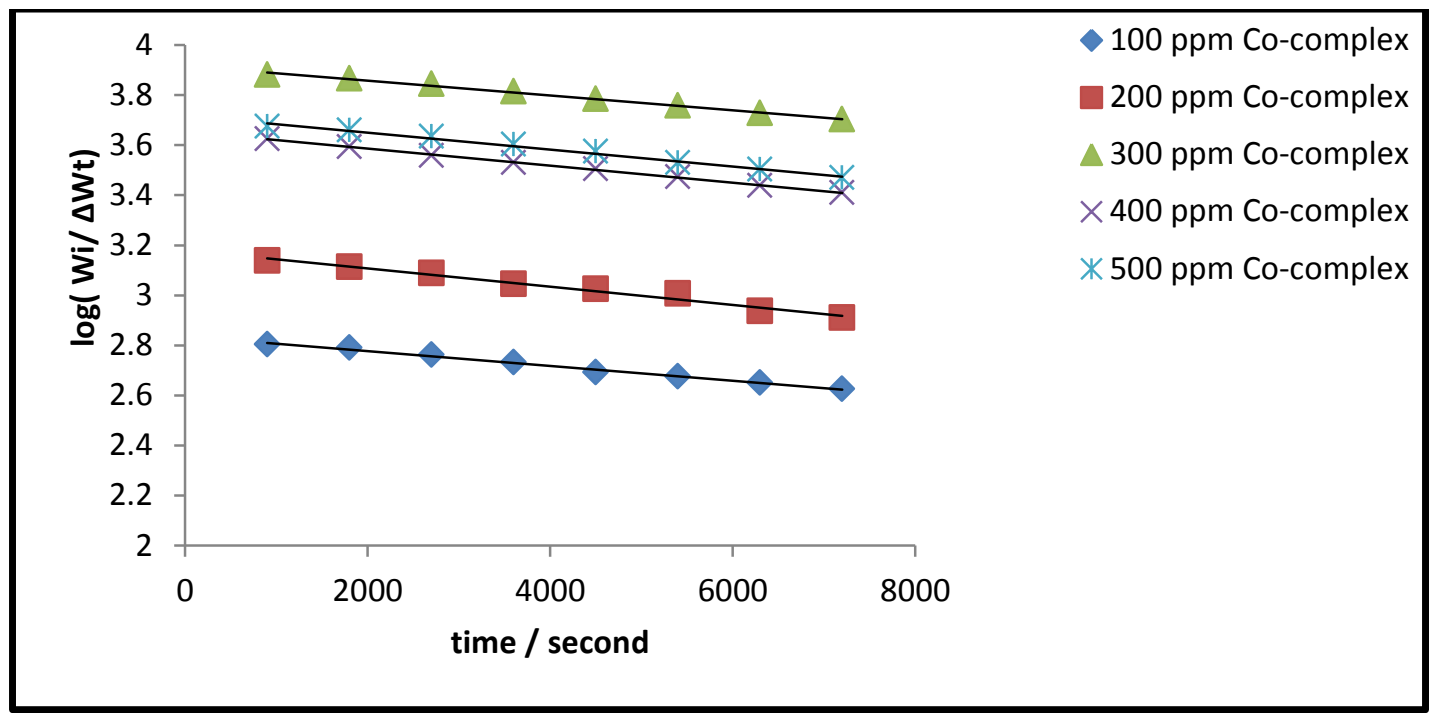

Fig.(8): Kinetic measurements of corrosion for carbon steel in $\mathrm{HCl}$ at different concentrations of Co-complexes.

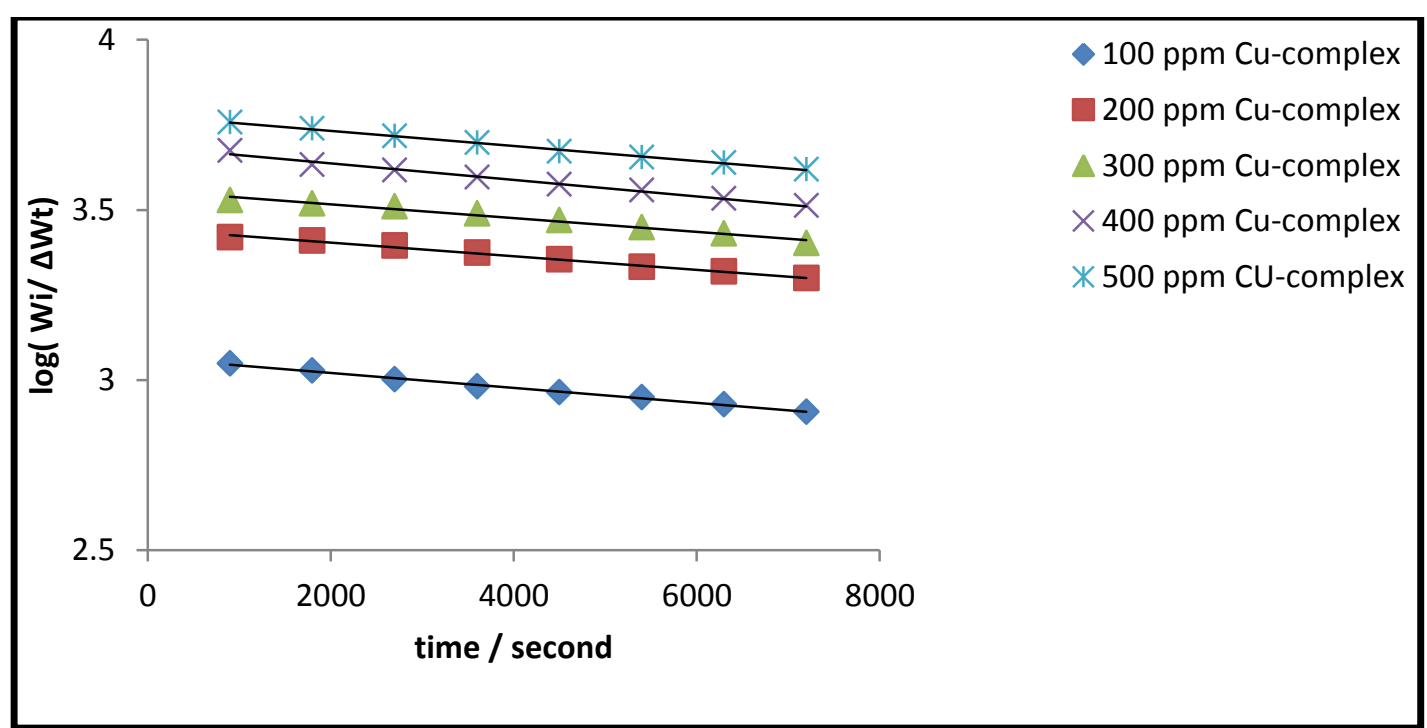

Fig.(9): Kinetic measurements of corrosion for carbon steel in $\mathrm{HCl}$ at different concentrations of $\mathrm{Cu}$-complexes. 
Table (4)

Kinetic measurements for carbon steel in 1M $\mathrm{HCl}$ with $\mathrm{Ni}$-, $\mathrm{Co}$ - and $\mathrm{Cu}$-complexes at different concentrations.

\begin{tabular}{|c|c|}
\hline Conc. (ppm) & $\mathrm{k}\left(\mathrm{s}^{-1}\right) \times 10^{-5}$ \\
\hline \multicolumn{2}{|c|}{ Ni-complexes } \\
\hline 100 & 5.56861 \\
\hline 200 & 5.11720 \\
\hline 300 & 5.11720 \\
\hline 400 & 5.11720 \\
\hline 500 & 5.11720 \\
\hline \multicolumn{2}{|c|}{ Co-complexes } \\
\hline 100 & 7.82144 \\
\hline 200 & 7.82144 \\
\hline 300 & 7.82007 \\
\hline 400 & 7.82007 \\
\hline 500 & 7.82007 \\
\hline \multicolumn{2}{|c|}{$\begin{array}{l}\mathrm{Cu} \text {-complexes } \\
\end{array}$} \\
\hline 100 & 5.08272 \\
\hline 200 & 5.08272 \\
\hline 300 & 5.08272 \\
\hline 400 & 5.08272 \\
\hline 500 & 5.08272 \\
\hline
\end{tabular}

Thermodynamic study of carbonic steel in acid medium with inhibitor:

Fig.(10) shows that adsorption of organic metal complexes on carbon steel surface follow Langmuir isotherm [25]:

$$
\left[\mathrm{C}_{\mathrm{inh}} / \Theta\right]=1 / \mathrm{k}_{\mathrm{ad}}+\mathrm{C}_{\mathrm{inh}}
$$

Where $\mathrm{k}_{\mathrm{ad}}$ is the equilibrium constant of adsorption constant, $\mathrm{C}_{\mathrm{inh}}$ the concentration of inhibitor and $\Theta$ is the surface coverage. According to eq. (4).We can calculate $\mathrm{k}_{\mathrm{ad}}$. From the intercept lines from fig.10, so we can calculate the Standard free energy of adsorption $\left(\Delta \mathrm{G}_{\text {ads }}^{0}\right)$ with following equation [26]:

$$
\Delta \mathrm{G}_{\mathrm{ads}}=-\mathrm{RT} \operatorname{In}\left(55.5 \mathrm{~K}_{\mathrm{ads}}\right)
$$

$\mathrm{R}$ is gas constant and $\mathrm{T}$ is absolute temperature. The value 55.5 is the concentration of water in solution in $\mathrm{mol} / \mathrm{dm}^{3}$. It is found that the $\Delta \mathrm{G}_{\mathrm{ads}}$ values for the using ligand and its complexes are less than $-40 \mathrm{~kJ}$ $\mathrm{mol}^{-1}$, the negative values of $\Delta \mathrm{G}_{\mathrm{ads}}$ show spontaneous adsorption of metal complexes onto carbon steel [27]. Values of calculated free energies are listed in Table (5).

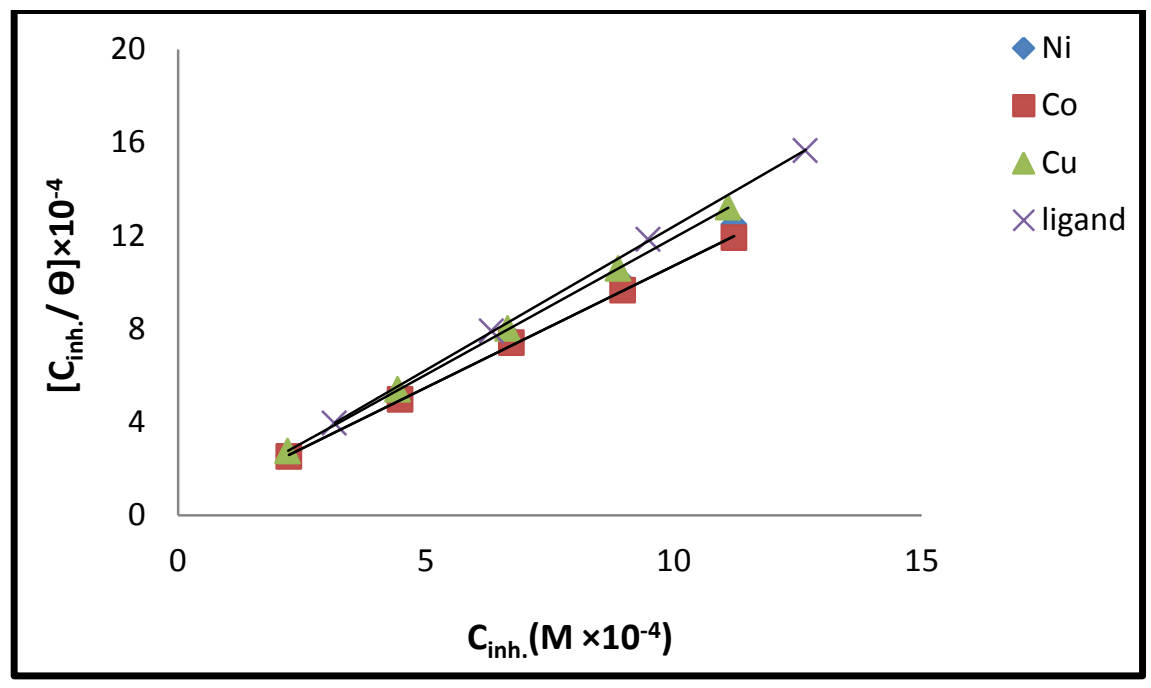

Fig.(10): Langmuir adsorption isotherm for carbon steel in $1 \mathrm{M} \mathrm{HCl}$ without and with metal complexes. 
Table (5)

Thermodynamic measurement of adsorption of metal complexes on carbon steel.

\begin{tabular}{||c||c|c|c||}
\hline Inhibitors & $\mathbf{R}^{\mathbf{2}}$ & $\begin{array}{c}\mathbf{K}_{\text {ads }} \\
\left(\mathbf{1 0}^{\mathbf{4}} \mathbf{M}^{-\mathbf{1}}\right)\end{array}$ & $\begin{array}{c}-\Delta \mathbf{G} / \\
\mathbf{k J ~ m o l}^{\mathbf{1}}\end{array}$ \\
\hline \hline Ni-Ligand & 0.9996 & 7.5019 & 37.763 \\
\hline \hline Co-Ligand & 0.9997 & 19.0114 & 40.066 \\
\hline Cu-Ligand & 0.9996 & 4.0634 & 36.244 \\
\hline \hline Ligand & 0.9999 & 1.7864 & 34.208 \\
\hline
\end{tabular}

\section{Scanning electron microscopy (SEM)}

SEM micrographs resulted from exposed and unexposed specimen in $1 \mathrm{M} \mathrm{HCl}$ for $(24$ hour) in the existence and inexistence of 500 ppm of the prepared ligand and its transition metal complexes are shown in Fig.(10). The scanning electron microscopy (SEM) has been used to study the morphology of the corroded surface in the existence and inexistence of inhibitor for the immersion of 24 hour at room temperature. The SEM images are taken from that portion of the specimen where good information is predictable. After corrosion tests, a surface analysis was carried out using scanning electron microscope, immediately. The rate corrosion (CR) was reduced extremely in the presence of inhibitors. It detect that there is a good preventative film adsorbed on metal surface, which acted as a barrier and was accountable for the inhibition of corrosion.

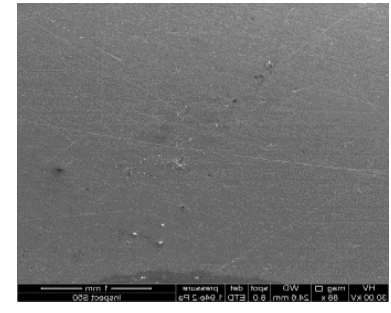

Ligand

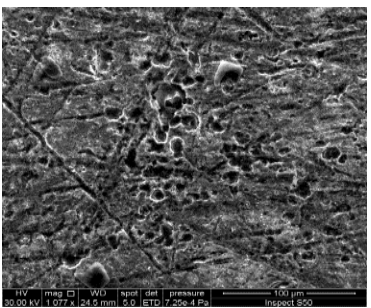

Co-complex

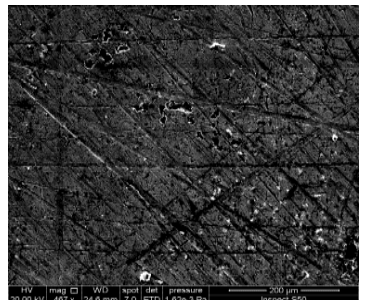

Without inhibitor

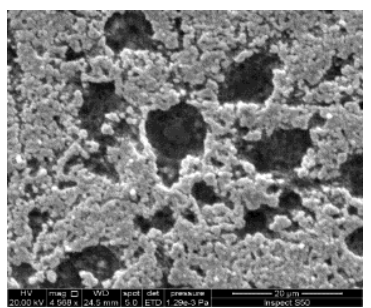

$\mathrm{Cu}$-complex

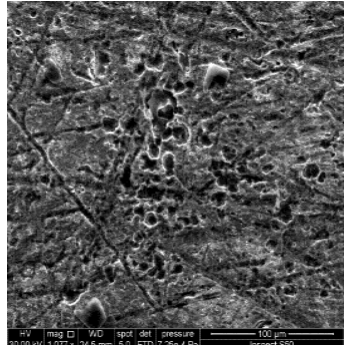

Ni-complex
Fig.(11): Scanning electron micrographs of Ligand and its Complexes on carbon steel alloy.

\section{Conclusions}

These conclusions may be estimate from this research:

1. Data gained show that metal complexes show efficient inhibitors.

2. Inhibition efficiency increases with the increase of concentrations of metal complexes.

3. The value of $\Delta G^{\circ}$ ads is negative so it signs to spontaneous adsorption on the surface of metal.

4. 4-SEM checking of carbon steel surface showed the existence of protective surface film formed on carbon steel alloy surface which inhibits metal degradation in $\mathrm{HCl}$.

\section{References}

[1] Fouda A.S., Diab M. A., Fathy S., Role of Some Organic Compounds as Corrosion Inhibitors for 316L Stainless Steelin $1 \mathrm{M}$ $\mathrm{HCl}$, Int. J. Electrochem. Sci., 12, 347 362, 2017. 
[2] Yadav M., Gope L., Kumari N., Yadav P., Corrosion inhibitionperformance of pyranopyrazole derivatives for mild steel in $\mathrm{HCl}$ solution: Gravimetric, electrochemical and DFT studies, ELSEVIER, Journal of Molecular Liquids, 216, 78-86,2016.

[3] Ezhilarasi M. R., Prabha B., Santhi T., Corrosive inhibitiveeffect of pyrazole compounds towards the corrosion of mildsteel in acidic medium, Rasayan Journal of chemistry, 8 (1),71-83, 2015.

[4] Saratha R., Meenakshi R. Dimethyl amino benzylideneacetone as corrosion inhibitor for mild steel in acid medium, Rasayan Journal of chemistry, 4(2), 251-263, 2011.

[5] Sherif .E.-S.M., Almajid. A.A., "Surface protection of copper in aerated $3.5 \%$ sodium chloride solutions by 3-amino-5mercapto-1, 2, 4-triazole asa copper corrosion inhibitor", J. Appl. Electrochem., 40, 1555-1562, 2010.

[6] Shukla .G. Ji, S.K., Dwivedi .P, Sundaram. S. Prakash. R., "Inhibitive effect of Argemone mexicana plant extract on acid corrosion of mild steel," Industrial \& Engineering Chemistry Research,. 50, 11954-9, 2011.

[7]Shukla. K., Ebenso. E., Corrosion Inhibition, Adsorption Behavior and Thermodynamic Properties of Streptomycin on Mild Steel in Hydrochloric Acid Medium, Int. J. Electrochem. Sci., 6, 3277 3291, 2011.

[8] Sherif. E.-S.M., R.M. Erasmus, J.D. Comins, "Corrosion of copper in aerated acidic pickling solutions and its inhibition by 3-amino-1, 2, 4-triazole-5-thiol", Journal of Colloid and Interface Science, 306, 96104, 2007.

[9]Khalifa. O. R., Abdallah .S. M., Corrosion Inhibition of Some Organic Compounds on Low Carbon Steel in. Hydrochloric Acid Solution, Portugaliae Electrochimica Acta29 1), 47-56, 2011.

[10] Ezhilarasi M. R., Prabha B., Santhi T., Corrosive inhibitive effect of pyrazole compounds towards the corrosion of mild steel in acidic medium, Rasayan Journal of chemistry, 8 (1), 71-83, 2015.

[11] Abd El Rehim S. S., Ibrahim M. A., Khalid M. K. F.,4-amino antipyrine as an inhibitor of mild steel corrosion in $\mathrm{HCl}$ solution, J. Appl. Electrochem., 29, 59, 1999.

[12] Zaafarany. I., Abdallah. M., Ethoxylated Fatty Amide as Corrosion Inhibitors for Carbon Steel in Hydrochloric Acid Solution, Int. J. Electrochem. Sci., 5, 18, 2010.

[13] Nageh Allam .K., Corrosion Protection on Copper by Imidazole and Its Derivatives, Applied Surface Science., 253, 4570,2010.

[14]Dina A., Ahmed A, Muhammad. R Yusop, Synthesis, Characterization and Theoretical Study of 1, 2 (2, 2-dihydroxy benzelidenamine) Phenyl Complexes, J. of AL-Nahrain University. 20,12-17, 2017.

[15] Scendo M., Corrosion inhibition of copper by purine or adenine in sulphate solutions, Corrosion Sci. 49, 3953-3968, 2007.

[16] Lodha .S. R., Weight Loss Measurement and Theoretical Study of New Pyridazine Compound as Corrosion Inhibitor for C38 Steel in Hydrochloric Acid Solution, Pharmaceutical Reviews. 6,1, 2008.

[17] Jacob K.S. and Parameswaran G., Corrosion inhibition of mild steel in hydrochloric acid solution by Schiff base furoin thiosemicarbazone, Corros. Sci, 52, 224-228, 2010.

[18] Shokry H., Yuasa M., Sekine I., Issa R.M., El-Baradie H.Y. and Gomma G.K., Corrosion inhibition of mild steel by Schiff base compounds in various aqueous Solutions, Corros. Sci, 39, 2173-2186 1998.

[19] Mahdavian M. and Attar M. M., Electrochemical behaviour of some transition metal acetylacetonate complexes as corrosion inhibitors for mild steel, Corros. Sci, 51, 409-414, 2009.

[20] Singh P. V., Singh P. and Singh A.K., Synthesis, structural and corrosion inhibition studies on cobalt(II), nickel(II), copper(II) and zinc(II) complexes with 2acetylthiophene benzoylhydrazone, Inorg. Chim. Acta, 379, 56-63, 2011.

[21] Singh P., Singh A.K. and Singh V.P., Synthesis, structural and corrosion inhibition properties of some transition metal (II) complexes with o- 
hydroxyacetophenone-2-thiophenoyl hydrazone, Polyhedron, 65, 73-81, 2013.

[22] Yiheyis, B., Nithyakalyani, D., Ananda, K., Synthesis, Structural Characterization, Corrosion inhibition and in vitro antimicrobial studies of 2-(5-Methoxy-2Hydroxybenzylideneamino) Phenol Schiff Base ligand and its transition metal complexes, International Journal of Chem Tech Research, 6 (11), 4569-4578, 2014.

[23] Mani, N., Venkatakrishna Iyer, S., Bahadur, L. Corrosive Inhibitive Study of Stainless Steel in Hydrochloric Acid Using Eco-Friendly Sesmum Indicum Oil, Transactions of the SAEST, 38(2), 67-71, 2003.

[24] Patil, D.B., Sharma, A.R., Study on the Corrosion Kinetics of Iron in Acid and Base Medium, E-Journal of Chemistry,8(S1), S358-S362, 2011.

[25] Guls_,A., Corrosion inhibition of indole3-acetic acid on mild steel in $0.5 \mathrm{M} \mathrm{HCl}$, Colloids and Surfaces A, Physicochemical and Engineering Aspects, 317, 730-736, 2008.

[26] Olivares. O., Likhanova. N. V., Gomez. B., J. Navarrete, M. E. Llanos-Serrano, E. Arce, J. M. Hallen, Corrosion inhibition of carbon steel in hydrochloric acid $0.5 \mathrm{M}$ by hexa methylene diamine tetramethylphosphonic acid, Appl. Surf. Sci. 252, 2894, 2006.

[27] Zarrok1. H., Salghi2.R., Zarrouk3.A., B., Hammouti3. H. Oudda1 , Bazzi4. Lh. Bammou., L.2,S.S. Al-Deyab. Investigation of the Inhibition Effect of N-1Naphthylethylenediamine Dihydrochloride Monomethanolate on the C38 Steel Corrosion in 0.5M H2SO4, Der Pharma Chemica, 4 (1):407-416, 2012. 